\title{
One-step nucleic acid amplification assay for intraoperative prediction of advanced axillary lymph node metastases in breast cancer patients with sentinel lymph node metastasis
}

\author{
MICHIYO KUBOTA $^{1}$, YOSHIFUMI KOMOIKE ${ }^{1}$, MIKA HAMADA ${ }^{1}$, WATARU SHINZAKI ${ }^{1}$, TATSUYA AZUMI ${ }^{1}$, \\ YUKIHIKO HASHIMOTO ${ }^{1}$, SHIGERU IMOTO ${ }^{2}$, YOSHIFUMI TAKEYAMA ${ }^{1}$ and KIYOTAKA OKUNO ${ }^{1}$ \\ ${ }^{1}$ Department of Surgery, Kinki University Faculty of Medicine, Osaka-Sayama, Osaka 589-8511; \\ ${ }^{2}$ Department of Breast Surgery, Kyorin University School of Medicine, Tokyo 192-8508, Japan
}

Received July 13, 2015; Accepted October 30, 2015

DOI: $10.3892 / \mathrm{mco} .2015 .694$

\begin{abstract}
The one-step nucleic acid amplification (OSNA) assay is used to semiquantitatively measure the cytokeratin (CK)19 mRNA copy numbers of each sentinel lymph node (SLN) in breast cancer patients. The aim of the present study was to evaluate whether the diagnosis of $\geq 4 \mathrm{LN}$ metastases is possible using the OSNA assay intraoperatively. Between May, 2010 and December, 2014, a total of 134 patients who underwent axillary lymph node dissection (ALND) of positive SLNs were analyzed. The total tumor load (TTL) was defined as the total CK19 mRNA copies of all positive SLNs. The correlation between TTL and $\geq 4 \mathrm{LN}$ metastases was evaluated. Of the 134 patients, 31 (23.1\%) had $\geq 4$ LN metastases. TTL $\geq 5.4 \times 10^{4}$ copies $/ \mu 1$ evaluated by receiver operator characteristic curve analysis was examined along with other clinicopathological variables. In the multivariate analysis, only TTL $\geq 5.4 \times 10^{4}$ copies $/ \mu 1$ was correlated with $\geq 4 \mathrm{LN}$ metastases (odds ratio $=2.95,95 \%$ confidence interval: $1.17-7.97, \mathrm{P}=0.022$ ). Therefore, TTL assessed by the OSNA assay has the potential to be a predictor of $\geq 4 \mathrm{LN}$ metastases and it may be useful for the selection of patients with positive SLNs in whom ALND may be safely omitted.
\end{abstract}

\section{Introduction}

Axillary surgery in breast cancer has transitioned from level III to level II dissection. Axillary lymph node dissection (ALND) is commonly associated with complications, such as sensory and motor nervous system disorders and edema of the arm. To avoid such complications, sentinel LN biopsy (SLNB) is accepted as a standard technique for clinically

Correspondence to: Dr Michiyo Kubota, Department of Surgery, Kinki University Faculty of Medicine, 377-2 Ohno-higashi, Osaka-Sayama, Osaka 589-8511, Japan

E-mail: m-kubota@surg.med.kindai.ac.jp

Key words: sentinel lymph node, axillary lymph node dissection, one-step nucleic acid amplification, total tumor load, breast cancer node-negative breast cancer patients. SLNB alone (without ALND) is currently the standard course of action for axillary management in patients with negative SLNs (1).

The American College of Surgeons Oncology Group (ACOSOG) Z0011 randomized controlled trial compared overall survival between patients with positive SLNs undergoing SLNB alone and those undergoing SLNB with ALND (2). The trial demonstrated that, for patients with stage T1-2 and $\leq 2$ metastatic SLNs who were treated with breast-conserving surgery followed by whole-breast irradiation and adjuvant systemic therapy, SLNB alone resulted in a similar disease-free and overall survival compared with ALND (2). Furthermore, the International Breast Cancer Study Group (IBCSG) 23-01 trial randomized patients with micrometastases to SLNB alone or ALND groups, and reported a similar disease-free survival for the two patient groups (3). Additionally, the European Organisation for Research and Treatment of Cancer 10981-22023 AMAROS trial compared the axillary recurrence rate between the ALND and axillary irradiation patient groups; both groups consisted of patients with positive SLNs, and the results of the trial demonstrated a similar disease-free and overall survival between the two, similar to the findings of the ACOSOG and IBCSG trials (4). Based on these results, the clinical significance of ALND has been reduced and the selection of patients with positive SLNs in whom ALND may be omitted is attracting increasing attention.

The presence of LN metastases is the most significant prognostic indicator for breast cancer and a major factor in determining adjuvant therapy. Previously, if the presence of LN metastasis was confirmed, postoperative chemotherapy was deemed essential. However, following the St. Gallen Consensus Conference in 2011, the intrinsic subtype of breast cancer has become a more important determinant of adjuvant therapy, rather than the presence of LN metastasis, although the presence of $\geq 4 \mathrm{LN}$ metastases remains an important indicator, as additional chemotherapy is recommended for such patients, regardless of the cancer subtype (5). Furthermore, when $\geq 4$ LN metastases are identified, irradiation of the supraand subclavian regions, in addition to the preserved breast, has been reported to improve patient survival as well as local 
disease control $(6,7)$. Therefore, it is important to determine whether $\geq 4 \mathrm{LN}$ metastases are present, in order to optimize treatment. Several previous studies have reported a number of methods to predict $\geq 4 \mathrm{LN}$ metastases (8-11). However, the majority of these relied on factors that were determined postoperatively, and are therefore not widely applied in clinical practice.

The one-step nucleic acid amplification (OSNA) assay is a method for diagnosing LN metastasis through solubilization of LNs and amplification and detection of cytokeratin (CK)19 mRNA. The OSNA assay is able to assess the entire LN, while histopathological examination usually evaluates only the maximum cut surface. The OSNA assay is completed in 30-40 min and is thus suitable for intraoperative diagnosis of SLN metastasis. Several previous studies have reported the usefulness of the OSNA assay for predicting the extent of LN metastasis based on its ability to semi-quantitatively measure CK19 mRNA copy number $(12-15,16)$.

The aim of the present study was to evaluate whether it is possible to intraoperatively diagnose the presence of $\geq 4 \mathrm{LN}$ metastases in breast cancer patients using the OSNA assay.

\section{Patients and methods}

Patients. A total of 621 patients with invasive breast cancer underwent SLNB evaluated by the OSNA assay between May, 2010 and December, 2014 at Kinki University Hospital, Osaka, Japan. Of the 621 patients, 134 who subsequently underwent ALND of the positive SLNs were analyzed. Patients who received neoadjuvant drug therapy, axillary LN sampling alone, and patients with non-invasive cancer, were excluded from this study. Staging was based on the 7th edition of the Union for International Cancer Control TNM classification of malignant tumors (17).

SLN detection. Detection of SLNs was performed using a radioisotope tracer (technetium-99m phytate) and dye (indocyanine green). The day prior to surgery, $85 \mathrm{MBq}(0.5 \mathrm{ml})$ of tracer was injected into the subdermal space in the outer border of the areola. Lymphoscintigraphy was performed $2 \mathrm{~h}$ following the injection. During surgery, $5 \mathrm{mg}(1 \mathrm{ml})$ of indocyanine green was injected into the subdermal space in the outer border of the areola and the SLNs were identified using a hand-held gamma probe and dye mapping. SLN metastases were evaluated intraoperatively using the OSNA assay, and ALND was performed when at least one SLN was found to be OSNA-positive (+ or ++ , as defined below).

SLN assessment. Whole SLNs were evaluated using the OSNA assay, as previously described (18). SLNs were assessed as OSNA-negative (CK19 mRNA $<2.5 \times 10^{2}$ copies $\left./ \mu 1\right)$, OSNA+ $\left(2.5 \times 10^{2}\right.$ to $<5.0 \times 10^{3}$ copies $\left./ \mu 1\right)$, and OSNA++ $\left(\geq 5.0 \times 10^{3}\right.$ copies $\left./ \mu 1\right)$. When an SLN was assessed as OSNA + inhibition $\left(+\mathrm{I} ; \geq 2.5 \times 10^{2}\right.$ copies $/ \mu 1$ in the diluted samples), the patients were excluded from the study, as the reading was not accurate. Total tumor load (TTL) was defined as the total number of CK19 mRNA copies in all positive SLNs. The SLN ratio was defined as the ratio of positive:removed SLNs. Non-SLN tissue sections were evaluated by hematoxylin and eosin staining.
Table I. Patient characteristics $(\mathrm{n}=134)$.

\begin{tabular}{|c|c|}
\hline Characteristics & No. $(\%)$ \\
\hline Age, years [median (range)] & $55.5(27-81)$ \\
\hline \multicolumn{2}{|l|}{ Menopausal status } \\
\hline Premenopausal & $51(38.1)$ \\
\hline Postmenopausal & $83(61.9)$ \\
\hline \multicolumn{2}{|l|}{ Estrogen receptor status } \\
\hline+ & $109(81.3)$ \\
\hline- & 25 (18.7) \\
\hline \multicolumn{2}{|l|}{ Progesterone receptor status } \\
\hline+ & $94(70.1)$ \\
\hline- & $40(29.9)$ \\
\hline \multicolumn{2}{|l|}{ HER2 status } \\
\hline+ & $29(21.6)$ \\
\hline- & $105(78.4)$ \\
\hline \multicolumn{2}{|l|}{ Breast cancer subtype } \\
\hline Luminal/HER2- & $95(70.9)$ \\
\hline Luminal/HER2+ & $20(14.9)$ \\
\hline HER2+ & $9(6.7)$ \\
\hline Triple-negative & $10(7.5)$ \\
\hline \multicolumn{2}{|l|}{ Type of breast surgery } \\
\hline Partial mastectomy & $70(52.2)$ \\
\hline Total mastectomy & $64(47.8)$ \\
\hline \multicolumn{2}{|l|}{ Clinical T classification } \\
\hline cT1 & $66(49.3)$ \\
\hline cT2 & $63(47.0)$ \\
\hline cT3 & $5(3.7)$ \\
\hline \multicolumn{2}{|l|}{ Clinical $\mathrm{N}$ classification } \\
\hline cNO & $59(44.0)$ \\
\hline cN1 suspected & $75(56.0)$ \\
\hline \multicolumn{2}{|l|}{ OSNA diagnosis } \\
\hline+ & $35(26.1)$ \\
\hline++ & $99(73.9)$ \\
\hline \multicolumn{2}{|l|}{ Histological grade } \\
\hline 1 & $22(16.5)$ \\
\hline 2 & $44(32.8)$ \\
\hline 3 & $24(17.9)$ \\
\hline Unknown & $44(32.8)$ \\
\hline \multicolumn{2}{|l|}{$\mathrm{Ki}-67$} \\
\hline$<20 \%$ & $46(34.3)$ \\
\hline$\geq 20 \%$ & $35(26.1)$ \\
\hline Unknown & $53(39.6)$ \\
\hline \multicolumn{2}{|l|}{ Lymphovascular invasion } \\
\hline No & $53(39.5)$ \\
\hline Yes & $79(59.0)$ \\
\hline Unknown & $2(1.5)$ \\
\hline \multicolumn{2}{|l|}{ Histological type } \\
\hline Ductal & $116(86.6)$ \\
\hline Lobular & $11(8.2)$ \\
\hline Other & 7 (5.2) \\
\hline
\end{tabular}

OSNA, one-step nucleic acid amplification. HER2, human epidermal growth factor receptor 2 . 
Table II. Univariate analysis of variables correlated with $\geq 4$ lymph node metastases.

\begin{tabular}{|c|c|c|c|}
\hline \multirow[b]{2}{*}{ Variables } & \multicolumn{2}{|c|}{ LN metastases, no. (\%) } & \multirow[b]{2}{*}{ P-value } \\
\hline & $<4(\mathrm{n}=103)$ & $\geq 4(\mathrm{n}=31)$ & \\
\hline Menopausal status & & & 0.177 \\
\hline Premenopausal & $36(70.6)$ & $15(29.4)$ & \\
\hline Postmenopausal & $67(80.7)$ & $16(19.3)$ & \\
\hline Clinical T classification & & & 0.010 \\
\hline $\mathrm{cT} 1$ & $57(86.4)$ & $9(13.6)$ & \\
\hline$\geq \mathrm{cT} 2$ & 46 (67.6) & $22(32.4)$ & \\
\hline Clinical N classification & & & 0.006 \\
\hline $\mathrm{cNO}$ & $52(88.1)$ & $7(11.9)$ & \\
\hline cN1 suspected & $51(68.0)$ & $24(32.0)$ & \\
\hline ER status & & & 0.909 \\
\hline+ & $84(77.1)$ & $25(22.9)$ & \\
\hline- & $19(76.0)$ & $6(24.0)$ & \\
\hline PR status & & & 0.910 \\
\hline+ & $72(76.6)$ & $22(23.4)$ & \\
\hline - & $31(77.5)$ & $9(22.5)$ & \\
\hline HER2 status & & & 0.102 \\
\hline+ & $19(65.5)$ & $10(34.5)$ & \\
\hline- & $84(80.0)$ & $21(20.0)$ & \\
\hline TTL (copies $/ \mu 1$ ) & & & 0.001 \\
\hline$<5.4 \times 10^{4}$ & $61(88.4)$ & $8(11.6)$ & \\
\hline$\geq 5.4 \times 10^{4}$ & $42(64.6)$ & $23(35.4)$ & \\
\hline Ki-67 & & & 0.144 \\
\hline$<20 \%$ & $39(84.8)$ & $7(15.2)$ & \\
\hline$\geq 20 \%$ & $25(71.4)$ & $10(28.6)$ & \\
\hline Histological grade & & & 0.339 \\
\hline$\leq 2$ & $53(80.3)$ & $13(19.7)$ & \\
\hline 3 & $17(70.8)$ & $7(29.2)$ & \\
\hline SLN ratio & & & 0.103 \\
\hline$<0.67$ & $34(91.9)$ & $3(8.1)$ & \\
\hline$\geq 0.67$ & $69(71.1)$ & $28(28.9)$ & \\
\hline Lymphovascular invasion & & & 0.063 \\
\hline No & $45(84.9)$ & $8(15.1)$ & \\
\hline Yes & $56(70.9)$ & $23(29.1)$ & \\
\hline
\end{tabular}

LN, lymph node; ER, estrogen receptor; PR, progesterone receptor; HER2, human epidermal growth factor receptor 2; SLN, sentinel lymph node; TTL, total tumor load.

Examination of clinical tumor size and axillary nodal status. Clinical tumor size was defined as the largest tumor size measured by magnetic resonance imaging, ultrasonography (US) or computed tomography (CT). Clinical axillary LN metastasis diagnosis was established using contrast-enhanced CT and US. If an LN was diagnosed as metastatic using fine-needle aspiration biopsy, SLNB was not performed.

Statistical analysis. JMP software version 11 (SAS Institute, Cary, NC, USA) was used for statistical analysis. Univariate and multivariate analyses (logistic regression model) were performed to assess the association of the variables with $\geq 4$ LN metastases. A P-value of $<0.05$ was considered to indicate statistically significant differences. The accuracy of the TTL was estimated by constructing a receiver operator characteristic (ROC) curve and measuring the area under the curve (AUC).

\section{Results}

Clinicopathological characteristics. Of the 621 patients who had SLNs evaluated using the OSNA assay, 170 (27.3\%) were OSNA-positive. Of these 170 patients, 61 (35.9\%) were found to be OSNA+, $102(60.0 \%)$ were OSNA++, and 7 (4.1\%) were 
Table III. Multivariate analysis of variables correlated with $\geq 4$ lymph node metastases.

\begin{tabular}{lccc}
\hline Variables & Odds ratio & $95 \%$ CI & P-value \\
\hline $\begin{array}{l}\text { Clinical T classification } \\
\text { cT1 }\end{array}$ & 2.39 & $0.98-6.15$ & 0.088 \\
$\geq \mathrm{cT} 2$ & & & \\
Clinical N classification & 2.31 & $0.88-6.57$ & 0.055 \\
cN0 & & & \\
cN1 suspected & & & \\
TTL (copies/ $\mu 1)$ & 2.95 & $1.17-7.97$ & 0.022 \\
$\quad<5.4 \times 10^{4}$ & & & \\
$\geq 5.4 \times 10^{4}$ & & & \\
\hline
\end{tabular}

CI, confidence interval; TTL, total tumor load.

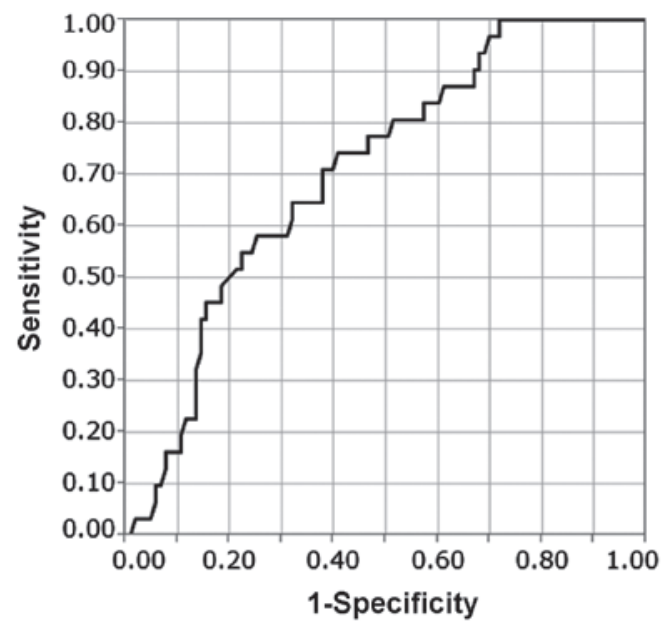

Figure 1. Receiver operator characteristic curve of the total tumor load. The area under the curve was 0.708 .

OSNA + I. Of the OSNA-positive patients, 134 (35 OSNA+ and 99 OSNA++) who underwent ALND were eligible for inclusion in our study (Table I). A total of 31 patients had one OSNA+ SLN, 4 patients had two OSNA+ SLNs, 62 patients had one OSNA++ SLN, 14 patients had two OSNA++ SLNs, 3 patients had three OSNA++ SLNs, 17 patients had one OSNA+ and one OSNA++ SLNs, and 3 patients had one OSNA+ and two OSNA++ SLNs. The median number of dissected LNs was 18.3 (range, 5-43). Of the 134 patients, 31 (23.1\%) had $\geq 4 \mathrm{LN}$ metastases.

Association between TTL and $\geq 4 L N$ metastases. The association between TTL and $\geq 4$ LN metastases was evaluated using ROC curve analysis (Fig. 1). The median of TTL was $4.5 \times 10^{4}$ copies $/ \mu 1\left(2.5 \times 10^{2}-6.0 \times 10^{6}\right)$. The AUC of the ROC curve was 0.708 and the TTL cut-off was $5.4 \times 10^{4}$ copies $/ \mu 1$. Of the patients with TTL $<5.4 \times 10^{4}$ copies $/ \mu 1,8(11.6 \%)$ had $\geq 4$ LN metastases and, of the patients with TTL $\geq 5.4 \times 10^{4}$ copies $/ \mu 1,23(35.4 \%)$ had $\geq 4$ LN metastases (Table II). With a TTL cut-off of $5.4 \times 10^{4}$ copies $/ \mu 1$, the sensitivity, specificity, positive and negative predictive values were $74,59,35$ and $88 \%$, respectively.
Variables correlated with $\geq 4$ LN metastases. The association between clinicopathological variables and $\geq 4$ LN metastases was evaluated. In the univariate analysis, clinical $\mathrm{T}$ classification (T1 vs. $\geq \mathrm{T} 2, \mathrm{P}=0.01)$, clinical $\mathrm{N}$ classification $(\mathrm{P}=0.006)$, and TTL $\geq 5.4 \times 10^{4}$ copies $/ \mu 1(\mathrm{P}=0.001)$ were correlated with $\geq 4$ LN metastases (Table II). In the multivariate analysis, TTL $\geq 5.4 \times 10^{4}$ copies $/ \mu 1$ was the only factor significantly correlated with $\geq 4 \mathrm{LN}$ metastases ( $\mathrm{OR}=2.95,95 \% \mathrm{CI}$ : 1.17-7.97, $\mathrm{P}=0.022$; Table III).

\section{Discussion}

A number of previous studies have reported on the prediction of non-SLN metastasis in SLN-positive patients. Osako et al demonstrated that SLN copy number, number of macrometastatic SLNs and lymphovascular invasion were significant factors for the identification of non-SLN metastasis (15). According to a meta-analysis of studies investigating non-SLN metastasis prediction, size of SLN metastasis $>2 \mathrm{~mm}$, extracapsular extension in SLNs, $\geq 2$ positive $\mathrm{SLNs}, \leq 1$ negative $\mathrm{SLN}$, tumor size $>2 \mathrm{~cm}$, ratio of positive SLNs $>50 \%$ and lymphovascular invasion in the primary tumor, have been reported to be strongly correlated with non-SLN metastasis (19).

It was previously reported that $\sim 50 \%$ of SLN-positive patients have non-SLN metastases $(20,21)$. However, even in patients with positive SLNs who did not undergo ALND, but instead received appropriate adjuvant therapy, the locoregional and distant recurrence rates were reported to be 1-2 and 5\%, respectively (3), which are significantly lower compared with those in patients with non-SLN metastases. Therefore, even in patients with non-SLN metastases, it is not always necessary to perform ALND. Thus, we hypothesized that it may be more important to predict $\geq 4 \mathrm{LN}$ metastases rather than non-SLN metastases, and conducted this study to evaluate the factors that predict the presence of $\geq 4 \mathrm{LN}$ metastases.

Several previous studies have focused on factors associated with $\geq 4 \mathrm{LN}$ metastases. Maretoja et al (8) reported an international multicenter predictive tool for the risk of $\geq 4 \mathrm{LN}$ metastases in patients with SLN macrometastases and demonstrated that the prevalence of $\geq 4 \mathrm{LN}$ metastases in each center, the number of positive SLNs, the number of negative SLNs, the histological size of the primary tumor and the presence of extracapsular extension of SLN metastases were strongly correlated with the presence of $\geq 4 \mathrm{LN}$ metastases. Furthermore, Katz et al (9) reported that the number of involved SLNs, extranodal extension, lymphovascular invasion, number of uninvolved SLNs, size of largest SLN metastasis, histology (lobular vs. other), and pathological tumor size were significant factors for identifying $\geq 4 \mathrm{LN}$ metastases.

In the present study, only TTL was significantly correlated with $\geq 4 \mathrm{LN}$ metastases. Our analysis demonstrated that pathological factors reported in previous studies (tumor size, histological grade, lymphovascular invasion and histology) were not correlated with $\geq 4 \mathrm{LN}$ metastases. Although extranodal extension of SLNs was shown to be correlated with $\geq 4$ LN metastases in a number of previous studies, SLNs were solubilized for the OSNA assay in the present study and, for this reason, it was not possible to evaluate extranodal extension. The SLN ratio, which has also been identified as an important 
factor in previous studies, was not found to be correlated with $\geq 4 \mathrm{LN}$ metastases in our analysis.

A number of the aforementioned factors are clinically confounding. For example, as the clinical tumor size and size of SLN metastases differed according to the imaging modality used, there is a limit to their accurate evaluation. Moreover, the majority of these factors, such as extranodal SLN extension, lymphovascular invasion and histological grade, are difficult to assess accurately, pre- or intra-operatively. Therefore, these factors cannot be used during surgery to determine the need for ALND.

In the present study, OSNA diagnosis was significantly correlated with $\geq 4 \mathrm{LN}$ metastases. Additionally, OSNA diagnosis was one of the factors correlated with $\geq 4 \mathrm{LN}$ metastases in the univariate analysis (data not shown). As the OSNA assay is an objective method that may be rapidly evaluated during surgery, it is useful for intraoperatively determining the necessity of ALND. An OSNA+ result corresponds to micrometastasis on histopathological examination (18) and, as a previous randomized controlled trial demonstrated, ALND is of no clinical significance with respect to disease-free survival and the survival rate of patients with micrometastases $(3,22,23)$. By contrast, for patients with SLN macrometastases, it is more important to identify those in whom ALND may be safely omitted. Therefore, we consider omission of ALND based on OSNA diagnosis alone to be inadequate.

The usefulness of TTL, assessed by the OSNA assay, was investigated as an alternative to OSNA diagnosis. TTL is considered to reflect the tumor burden in LNs more accurately compared with the number of copies of one SLN. Furthermore, TTL has been previously reported to be useful for predicting the extent of LN metastases. Peg et al (16) reported that TTL is an independent predictor of non-SLN metastasis and, if patients have TTL $\geq 1.5 \times 10^{4}$ copies $/ \mu 1$, non-SLN metastasis occurs at a higher frequency. Similar studies have reported a correlation between TTL and non-SLN metastasis $(13,15)$. In the present study, we evaluated the association between TTL and $\geq 4$ LN metastases, and found it to be significant when TTL $\geq 5.4 \times 10^{4}$ copies $/ \mu 1$. Ohi et al (14) investigated the correlation between $\geq 4 \mathrm{LN}$ metastases and the maximum copy number of SLNs, and reported that $1.0 \times 10^{5}$ copies $/ \mu 1$ were correlated with $\geq 4$ LN metastases; however, they only evaluated one SLN, namely the one with the maximum number of copies. We consider that the total copy number of all the SLNs is more significantly correlated with the extent of LN metastases compared with the maximum copies of one SLN. To the best of our knowledge, the present study was the first to investigate the correlation between TTL and $\geq 4$ LN metastases. We demonstrated that, of the patients with TTL $>5.4 \times 104$ copies $/ \mu 1,23$ (35.4\%) had $\geq 4$ LN metastases, which suggests that ALND cannot be omitted in these cases.

There major limitation of our study was the AUC of TTL, which was 0.708 , and is of moderate accuracy. The development of novel molecular markers associated with LN metastases may improve the accuracy of the TTL.

In conclusion, $\mathrm{TTL} \geq 5.4 \times 10^{4}$ copies/ $\mu 1$ significantly correlated with $\geq 4 \mathrm{LN}$ metastases. Therefore, TTL is likely to become an objective tool for intraoperatively deciding the omission of ALND in SLN-positive breast cancer patients. Further studies are required to improve the accuracy of this assessment.

\section{Acknowledgements}

The present study was supported in part by grants-in-aid for scientific research from the Japanese Breast Cancer Society.

\section{References}

1. Lyman GH, Giuliano AE, Somerfield MR, Benson AB III, Bodurka DC, Burstein HJ, Cochran AJ, Cody HS III, Edge SB, Galper S, et al; American Society of Clinical Oncology: American Society of Clinical Oncology guideline recommendations for sentinel lymph node biopsy in early-stage breast cancer. J Clin Oncol 23: 7703-7720, 2005.

2. Giuliano AE, Hunt KK, Ballman KV, Beitsch PD, Whitworth PW, Blumencranz PW, Leitch AM, Saha S, McCall LM and Morrow M: Axillary dissection vs. no axillary dissection in women with invasive breast cancer and sentinel node metastasis: A randomized clinical trial. JAMA 305: 569-579, 2011.

3. Galimberti V, Cole BF, Zurrida S, Viale G, Luini A, Veronesi P, Baratella P, Chifu C, Sargenti M, Intra M, et al: Axillary dissection versus no axillary dissection in patients with sentinel-node micrometastases (IBCSG 23-01): A phase 3 randomised controlled trial. Lancet Oncol 14: 297-305, 2013.

4. Donker M, van Tienhoven G, Straver ME, Meijnen P, van de Velde CJ, Mansel RE, Cataliotti L, Westenberg AH, Klinkenbijl JH, Orzalesi L, et al: Radiotherapy or surgery of the axilla after a positive sentinel node in breast cancer (EORTC 10981-22023 AMAROS): A randomised, multicentre, open-label, phase 3 non-inferiority trial. Lancet Oncol 15: 1303-1310, 2014

5. Goldhirsch A, Wood WC, Coates AS, Gelber RD, Thürlimann B and Senn HJ; Panel members: Strategies for subtypes - dealing with the diversity of breast cancer: Highlights of the St. Gallen International Expert Consensus on the Primary Therapy of Early Breast Cancer 2011. Ann Oncol 22: 1736-1747, 2011.

6. Overgaard M, Nielsen HM and Overgaard J: Is the benefit of postmastectomy irradiation limited to patients with four or more positive nodes, as recommended in international consensus reports? A subgroup analysis of the DBCG 82 b\&c randomized trials. Radiother Oncol 82: 247-253, 2007.

7. Recht A, Edge SB, Solin LJ, Robinson DS, Estabrook A, Fine RE, Fleming GF, Formenti S, Hudis C, Kirshner JJ, et al: Postmastectomy radiotherapy: Clinical practice guidelines of the American Society of Clinical Oncology. J Clin Oncol 19: 1539-1569, 2001.

8. Meretoja TJ, Audisio RA, Heikkilä PS, Bori R, Sejben I, Regitnig P, Luschin-Ebengreuth G, Zgajnar J, Perhavec A, Gazic B, et al: International multicenter tool to predict the risk of four or more tumor-positive axillary lymph nodes in breast cancer patients with sentinel node macrometastases. Breast Cancer Res Treat 138: 817-827, 2013.

9. Katz A, Smith BL, Golshan M, Niemierko A, Kobayashi W, Raad RA, Kelada A, Rizk L, Wong JS, Bellon JR, et al: Nomogram for the prediction of having four or more involved nodes for sentinel lymph node-positive breast cancer. J Clin Oncol 26: 2093-2098, 2008.

10. Chagpar AB, Scoggins CR, Martin RC II, Cook EF, McCurry T, Mizuguchi N, Paris KJ, Carlson DJ, Laidley AL, El-Eid SE, et al: Predicting patients at low probability of requiring postmastectomy radiation therapy. Ann Surg Oncol 14: 670-677, 2007.

11. Rivers AK, Griffith KA, Hunt KK, Degnim AC, Sabel MS, Diehl KM,Cimmino VM, Chang AE, Lucas PC and Newman LA: Clinicopathologic features associated with having four or more metastatic axillary nodes in breast cancer patients with a positive sentinel lymph node. Ann Surg Oncol 13: 36-44, 2006.

12. Sagara Y, Ohi Y, Matsukata A, Yotsumoto D, Baba S, Tamada S, Sagara Y, Matsuyama Y, Ando M, Rai Y and Sagara Y: Clinical application of the one-step nucleic acid amplification method to detect sentinel lymph node metastasis in breast cancer. Breast Cancer 20: 181-186, 2013.

13. Espinosa-Bravo M, Sansano I, Pérez-Hoyos S, Ramos M, Sancho M, Xercavins J, Rubio IT and Peg V: Prediction of non-sentinel lymph node metastasis in early breast cancer by assessing total tumoral load in the sentinel lymph node by molecular assay. Eur J Surg Oncol 39: 766-773, 2013. 
14. Ohi Y, Umekita Y, Sagara Y, Rai Y, Yotsumoto D, Matsukata A Baba S, Tamada S, Matsuyama Y, Ando M, et al: Whole sentinel lymph node analysis by a molecular assay predicts axillary node status in breast cancer. Br J Cancer 107: 1239-1243, 2012.

15. Osako T, Iwase T, Kimura K, Horii R and Akiyama F: Sentinel node tumour burden quantified based on cytokeratin 19 mRNA copy number predicts non-sentinel node metastases in breast cancer: Molecular whole-node analysis of all removed nodes. Eur J Cancer 49: 1187-1195, 2013.

16. Peg V, Espinosa-Bravo M, Vieites B, Vilardell F, Antúnez JR, de Salas MS, Delgado-Sánchez JJ, Pinto W, Gozalbo F, Petit A, et al: Intraoperative molecular analysis of total tumor load in sentinel lymph node: A new predictor of axillary status in early breast cancer patients. Breast Cancer Res Treat 139: 87-93, 2013.

17. Sobin LH, Gospodarowicz MK and Wittekind C (eds): UICC International Union Against Cancer TMN Classification of Malignant Tumours. 7th edition. Wiley-Blackwell, Hoboken, NJ, pp181-193, 2009.

18. Tsujimoto M, Nakabayashi $\mathrm{K}$, Yoshidome $\mathrm{K}$, Kaneko T, Iwase $\mathrm{T}$, Akiyama F, Kato Y, Tsuda H, Ueda S, Sato K, et al: One-step nucleic acid amplification for intraoperative detection of lymph node metastasis in breast cancer patients. Clin Cancer Res 13: 4807-4816, 2007.

19. van la Parra RF, Peer PG, Ernst MF and Bosscha K: Meta-analysis of predictive factors for non-sentinel lymph node metastases in breast cancer patients with a positive SLN. Eur J Surg Oncol 37: 290-299, 2011
20. Chu KU, Turner RR, Hansen NM, Brennan MB, Bilchik A and Giuliano AE: Do all patients with sentinel node metastasis from breast carcinoma need complete axillary node dissection? Ann Surg 229: 536-541, 1999.

21. Reynolds C, Mick R, Donohue JH, Grant CS, Farley DR, Callans LS, Orel SG, Keeney GL, Lawton TJ and Czerniecki BJ: Sentinel lymph node biopsy with metastasis: Can axillary dissection be avoided in some patients with breast cancer? J Clin Oncol 17: 1720-1726, 1999.

22. Yi M, Giordano SH, Meric-Bernstam F, Mittendorf EA, Kuerer HM, Hwang RF, Bedrosian I, Rourke L and Hunt KK: Trends in and outcomes from sentinel lymph node biopsy (SLNB) alone vs. SLNB with axillary lymph node dissection for node-positive breast cancer patients: Experience from the SEER database. Ann Surg Oncol 17 (Suppl 3): S343-S351, 2010.

23. Bilimoria KY, Bentrem DJ, Hansen NM, Bethke KP Rademaker AW, Ko CY, Winchester DP and Winchester DJ: Comparison of sentinel lymph node biopsy alone and completion axillary lymph node dissection for node-positive breast cancer. J Clin Oncol 27: 2946-2953, 2009. 